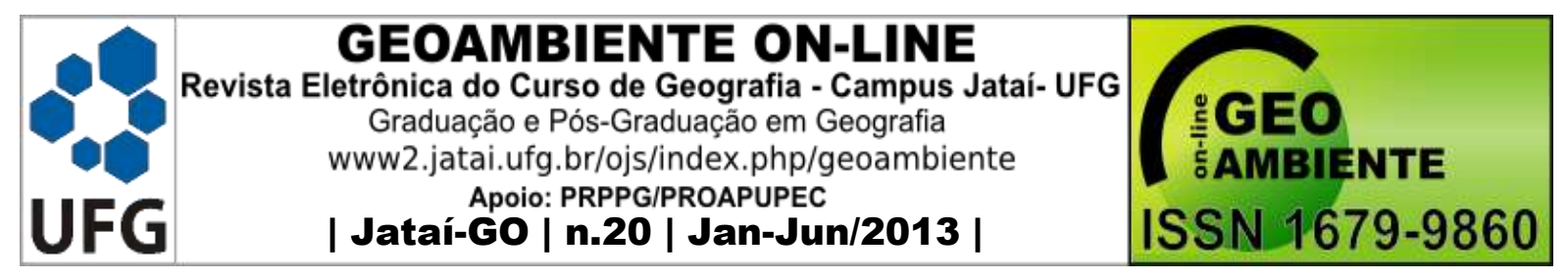

\title{
AVALIAÇÃO DE RISCO EM CENTRAL DE TRIAGEM DE PRODUTOS RECICLÁVEIS
}

Tattiana Lupion Torres; Caroline Linke; Josiani Cordova de Oliveira.

(Universidade do Estado de Santa Catarina, Programa de Mestrado em Engenharia Florestal, tatti_torres@terra.com.br; carolinelinke@ hotmail.com; josiani.oliv@gmail.com)

\section{Resumo}

O presente trabalho trata da avaliação de risco em uma área de central de reciclagem, onde são vários os fatores aos quais os funcionários que realizam a atividade estão expostos. Tem como objetivo identificar e avaliar os riscos presentes em uma área de central de reciclagem, além de sugerir medidas que podem ser tomadas para minimizá-los. Para classificação dos perigos e riscos foi utilizada uma tabela de probabilidade e severidade. A probabilidade é classificada de 1 a 7 , sendo que classificada em 1 ela pode ocorrer mais que dez vezes no ano e em 7 pode ocorrer dentro do próximo mês; já a severidade é classificada em alta, media e baixa, sendo que baixo é menor risco e efeito à saúde e alto são perdas permanentes, tais como amputações, paralisias e mortes. Após essa classificação, os riscos são então considerados como desprezível (não é necessário agir), baixo (deve-se monitorar os controles existentes), médio (deve-se melhorar os controles existentes), alto (deve-se reduzir os riscos) e crítico (adequar a operação). Após concluir esta classificação foram selecionados os riscos considerados altos e críticos para que medidas fossem propostas, apoiadas nas NBR 10; NBR 35; NBR 6. De acordo com os dados avaliados chegou-se a conclusão que á central pode ser classificada como uma área de risco médio se tomados os cuidados (uso de EPIs e EPC`s, e capacitação dos funcionários) para reduzir as atividades de alto risco.

Palavras-chave: Avaliação de risco; Perigo; Central de Reciclagem.

\section{Abstract}

RISK ASSESSMENT IN CENTRAL SORTING PRODUCTS RECYCLABLES

Artigo recebido para publicação em 15 de março de 2013 Artigo aprovado para publicação em 24 de junho de 2013 
The present work deals with the risk assessment in an area of central recycling, where there are several factors to which the employees who perform the activity are exposed. Aims to identify and assess the risks present in an area of central recycling and what measures can be taken to minimize them. For classification of hazards and risks was used a table of probability and severity. The probability is rated 1-7, and ranked 1st it can occur more than ten times a year and 7 may occur within the next month, since the severity is classified into high, medium and low, and low is lower risk and health effects and high losses are permanent, such as amputations, paralysis and death. After this classification, the risks are then considered as negligible (no action is required), low (should monitor existing controls), medium (should improve existing controls) high (due to reduce risk), and critical (adjust the operation). After completing this classification were selected risks are considered high and critical in order to propose measures, support in NBR 10, NBR 35, NBR 6.

Keywords: Risk assessment; Danger; Central Recycling.

\section{Resumen}

\section{EVALUACIÓN DE RIESGOS EN CENTRALES CLASIFICANDO PRODUCTOS RECICLABLES}

El presente trabajo se ocupa de la evaluación de riesgos en un área de reciclaje en el centro, donde hay varios factores a los que los empleados que realizan la actividad están expuestas. Tiene como objetivo identificar y evaluar los riesgos presentes en un área de centro de reciclaje y qué medidas se pueden tomar para minimizarlas. Para la clasificación de los peligros y riesgos que se utilizó una tabla de probabilidad y severidad. La probabilidad tiene 1-7 y está clasificado primero que puede aparecer más de diez veces al año y 7 pueden ocurrir en los próximos meses, ya que la gravedad se clasifica en alta, media y baja, y baja es menor riesgos y efectos sobre la salud y pérdidas altas son permanentes, como amputaciones, parálisis y muerte. Después de esta clasificación, los riesgos son, por consiguiente insignificante (no se requiere acción), baja (debe supervisar los controles existentes), mediano (debe mejorar los controles existentes) alta (debido a la reducción de riesgos), y crítica (ajustar el funcionamiento). Después de completar esta clasificación fueron los riesgos seleccionados se considera alta y crítica, a fin de proponer medidas de apoyo en NBR 10, NBR 35, NBR 6.

Palabras-claves: La evaluación de riesgos; Peligro; Reciclaje central. 


\section{Introdução}

Com a Revolução Industrial, a produtividade e o lucro passaram a ser prioridade para as empresas e o ser humano e as condições de trabalho ficaram em segundo plano. Segundo Engels (1985), nesse período os ambientes de trabalho constituíam espaços sem higiene, insalubres e perigosos, o que fez com que o número de acidentes de trabalho crescesse consideravelmente.

A partir daí teve início um processo de avaliação das condições de trabalho. Conforme Engels (1985), em meados do século XIX, foram verificados com maior consciência os efeitos das más condições de trabalho, sendo adotadas medidas de proteção sobre situações sujeitas a riscos graves. Nesse período iniciou-se a formação das corporações do trabalho nos países europeus.

No início do século XX, com o taylorismo, apareceram as primeiras noções de higiene e segurança do trabalho. Em 1954 nos Estados Unidos da América, Frank Bird Jr., estudioso da área de seguros, realizou um estudo sobre probabilidade de ocorrência de acidentes e incidentes. Na década de 1990, surgiram as normas internacionais elaboradas pela ISO (International Standard Organization), a ISO 14.000 e 18.000, além da norma Inglesa BS 8800 ( British Standart) publicada pelo HSE-UK (Health and Safety Executive United Kingdom) e as normas da série OHSAS 18.000 (Occupational Health and Safety Analysis).

As normas BSI (British Standard Institution), OHSAS 18001 e BS 8800, definem acidente como "evento indesejável que resulta em morte, problemas de saúde, ferimentos, danos e outros prejuízos".

O termo 'quase acidente', de acordo com as normas BSI, OHSAS 18001 e BS 8800, pode ser definido como "um evento não previsto que tinha potencial de gerar acidentes". Sendo assim, os acidentes são precedidos por incidentes ou "quase acidentes" que, por algum motivo, não provocaram perdas materiais ou lesões a pessoas. Tais situações, se não tratadas de forma adequada, podem vir a se agravar levando à ocorrência de acidentes fatais.

Uma das formas utilizadas para avaliar a correlação da quantidade de incidentes e acidentes é a pirâmide de Bird, a qual afirma que cada incidente poderia ter sido um acidente e só não o foi por uma questão de "sorte". Segundo a estatística de Bird, os acidentes com lesão leves ocorrem em um número menor do que as com danos de maior 
gravidade, e esta proporção seria de 600 (incidentes) para 30 (pequenos acidentes) para 10 (ferimentos leves) para 1 (fatal).

A fim de tratar os incidentes e acidentes de menor gravidade para evitar acidentes graves, o presente trabalho discute sobre as formas de identificar e tratar riscos antes mesmo de eles se tornarem acidentes, através da metodologia de avaliação de riscos.

De acordo com a Previdência Social, máquinas e equipamentos obsoletos e inseguros são responsáveis por cerca de $25 \%$ dos acidentes do trabalho graves e incapacitantes registrados no País. Dentre as máquinas analisadas de 2002 a 2005, as que provocaram maior número de acidentes foram as prensas e similares, que lideraram o ranking com $21 \%$. As principais causas foram: não utilização dos equipamentos de proteção; desobediência a procedimentos; negligência e imprudência pessoal; terceirização; construção civil; máquinas perigosas sem dispositivos de segurança; quebras mecânicas; falhas elétricas; acionamentos inadequados (Ministério do Trabalho e Emprego).

Segundo Velloso et al. (1997), na cidade do Rio de Janeiro, os dados referentes a CAT (Comunicação de Acidente do Trabalho) evidenciam como causa de maior incidência de acidentes os relacionados a resíduos sólidos e ao acondicionamento inadequado de lixo $(73 \%)$.

Em todas as operações de gerenciamento de resíduos, a exposição a poeiras orgânicas e micro-organismos pode ser causadora de doenças respiratórias. Estudo realizado em uma planta de separação de resíduos na Dinamarca revelou que 53\% dos trabalhadores desenvolveram doença pulmonar durante os oito primeiros meses de produção (ANJOS et al., 2000).

Conforme e Kuijer \& Frings-Dresen 1 (2004) apud Cardozo et al. (2005), nos EUA, a atividade de coleta de lixo é a sétima mais perigosa, sendo o risco de morte para o coletor 10 vezes maior em relação às demais ocupações americanas.

No estudo realizado por Santos et al. (2009) com trabalhadores da coleta de resíduos, os relativamente jovens, 67\%, se queixavam de dores no corpo (joelho, pernas, coluna) e $54 \%$, de cansaço crônico.

Com este estudo, almeja-se, sobretudo, contribuir para que os trabalhadores da área de central de reciclagem sejam respeitados, valorizados, já que seu trabalho é de extrema

1 KUIJER, P. P.; FRINGS-DRESEN, M. H. World at work: refuse collectors. Occupational \& Environmental Medicine, v.61, n.3, p.282-286, 2004. 
necessidade para a gestão de resíduos sólidos da empresa, a fim de minimizar os impactos ambientais e a geração de resíduos. A exposição aos riscos é frequente em suas atividades, mas esses riscos podem ser minimizados com atitudes conjuntas.

Assim, este trabalho busca conhecer as possíveis ações que contribuam para a minimização desses riscos e, efetivamente, contribuir para a melhoria da saúde e segurança dos trabalhadores.

\section{Material e métodos}

O presente trabalho foi realizado na área central de reciclagem de uma indústria alimentícia que conta com um total de 930 funcionários próprios e 430 funcionários terceirizados. $\mathrm{Na}$ área central de reciclagem 32 funcionários tercerizados, trabalham em três turnos, nas atividades de coleta seletiva, quebra de vidro, prensa e moinho de reciclagem, limpeza e organização da área, carregamento de caminhão, operação de empilhadeira etc.

Conforme Araújo (2002), com vistas a suprir as necessidades da indústria, vêm surgindo algumas propostas de planos de sistema de gestão de segurança e saúde dos trabalhadores, sendo os de maior destaque: BS 8800 (DE CICCO, 1996), Plano de Segurança e Saúde na Construção (DIAS; FONSECA, 1996), Programa Efetivo de Segurança para a construção (HINZE, 1997), OHSAS, 18001 (DE CICCO, 1999).

Encontram-se ainda como referência os seguintes autores e suas publicações: Brown, Curso de análise de risco (1991), Guilherme, Fundamentos da análise de risco (2005), Agência Europeia para a Segurança e a Saúde no Trabalho Avaliação de riscos: a chave para locais de trabalho seguros e saudáveis (2008); Rita Freitas, Avaliação de Risco, FIO (2002).

Segundo a Agência Europeia para a Segurança e a Saúde no Trabalho (2008), a metodologia utilizada para avaliação de risco deve ser dar em cinco etapas:

- Etapa 1 - Identificação dos perigos e das pessoas em risco.

- Etapa 2 - Avaliação e priorização dos riscos.

- Etapa 3 - Decisão sobre medidas preventivas.

- Etapa 4 - Adoção de medidas.

- Etapa 5 - Acompanhamento e revisão.

A metodologia utilizada para a avaliação de risco neste trabalho foi baseada nos autores citados acima e é composta por seis etapas: 
- Etapa 1 - Coleta de informações.

- Etapa 2 - Indicação dos riscos.

- Etapa 3 - Avaliação dos riscos decorrentes dos perigos.

- Etapa 4 - Definição e planejamento das ações para eliminar ou reduzir os riscos.

- Etapa 5 - Registro da avaliação de riscos.

- Etapa 6 - Revisão da avaliação de riscos.

Para a etapa 1, coleta de informações, foram levados em conta os tipos de processos existentes; materiais e equipamentos utilizados; o local onde o trabalho e (ou) as atividades são executadas; tipo de atividade; perfil dos colaboradores envolvidos levando em conta sexo, idade, tempo na função, trabalhadores temporários, turno de trabalho, funcionários com deficiência etc. Procurou-se levantar, ainda, quais os acidentes e incidentes já foram reportados, quais as medidas de proteção já adotadas e quais requisitos legais estão relacionados com o local de trabalho.

Essas informações foram coletadas por meio de fichas de informações de segurança de produtos químicos, manuais de trabalho dos equipamentos, monitoramentos no local de trabalho (ruído, temperatura etc.), comportamento dos operadores e entrevista de funcionários.

A segunda etapa, de identificação dos riscos, foi feita mediante um check list em que são identificados fatores humanos (comportamentais/ergonômicos), condições do ambiente e identificação dos riscos mais detalhados das atividades e máquinas.

De acordo com a Portaria n. ${ }^{\circ}$ 25, de 29 de dezembro de 1994, do Ministério do Trabalho e Emprego, obteve-se a tabela com a classificação dos principais riscos ocupacionais em grupos, de acordo com a sua natureza e a padronização das cores correspondentes. Juntamente com as classificações, colocam-se as principais consequências.

Durante o processo de avaliação dos riscos, na etapa 3 , foram consideradas a extensão do risco, a severidade, a probabilidade e a duração. Questões como violação de regulamentações, custo e dificuldade para reverter também foram fatores considerados. $\mathrm{Na}$ sequência, pode-se verificar na Figura 1 como foram definidas as classificações dos riscos pela probabilidade e severidade; na Figura 2 como foram classificados; e na Figura 3 como foram priorizados. 
Figura 1. Matriz de priorização

\begin{tabular}{|c|c|c|c|c|}
\hline \multicolumn{5}{|c|}{ Tabela de Prioridade } \\
\hline \multirow{7}{*}{$\begin{array}{l}\frac{1}{0} \\
\frac{\pi}{0} \\
\frac{0}{0} \\
\frac{0}{0} \\
\frac{0}{0} \\
\frac{2}{2}\end{array}$} & 7 & 7 & 14 & 21 \\
\hline & 6 & 6 & 12 & 18 \\
\hline & 5 & 5 & 10 & 15 \\
\hline & 4 & 4 & 8 & 12 \\
\hline & 3 & 3 & 6 & 9 \\
\hline & 2 & 2 & 4 & 6 \\
\hline & 1 & 1 & 2 & 3 \\
\hline & & 1 - Baixo & 2 - Médio & 3 - Alto \\
\hline & & \multicolumn{3}{|c|}{ Severidade } \\
\hline
\end{tabular}

Fonte: Adaptada de Brown (1991), Guilherme (2005), Agência Europeia para a Segurança e a Saúde no Trabalho Avaliação de riscos : a chave para locais de trabalho seguros e saudáveis (2008); Freitas (2002).

Figura 2. Matriz de análise de risco

7: Até 1 mês

6: Até 3 meses

5: Até 1 ano

4: Até 2 anos

3: Até 5 anos

2: Até 10 anos

$1:<10$ anos
Matriz de Análise de Risco
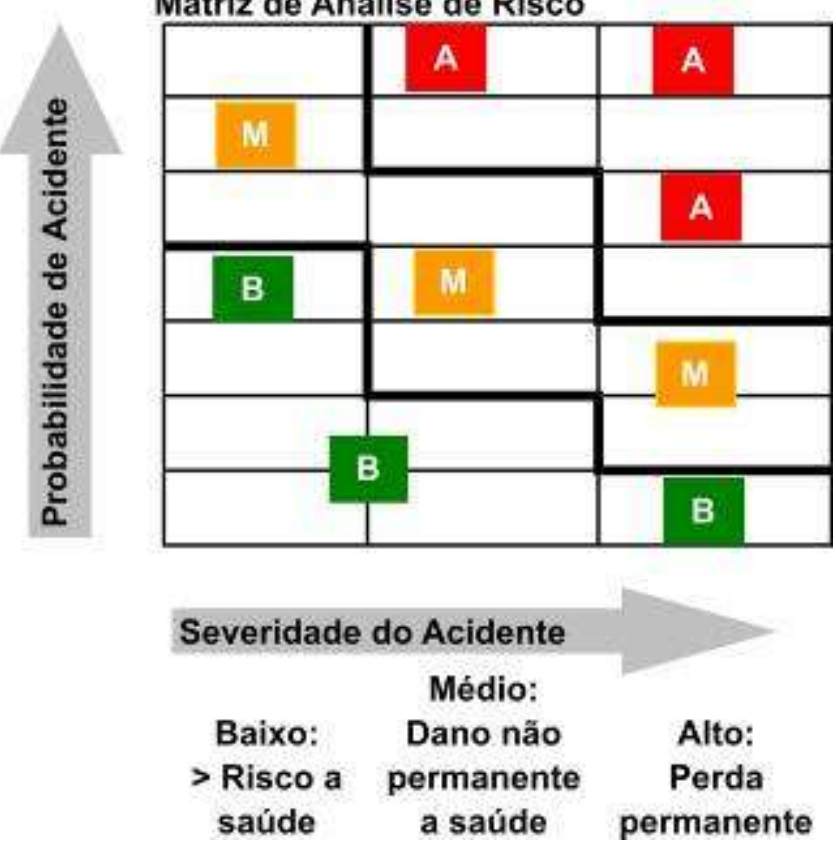

Fonte: Adaptada de Brown (1991), Guilherme (2005), Agência Europeia para a Segurança e a Saúde no Trabalho Avaliação de riscos : a chave para locais de trabalho seguros e saudáveis (2008); Freitas (2002).

Figura 3. Tabela de priorização

\begin{tabular}{|c|c|c|c|}
\hline \multicolumn{2}{|c|}{ Prioridade } & Ação & Prazo \\
\hline Branco & Desprezivel & Não precisa tomar açōes & - \\
\hline Verde & Baixo & Acompanhar medidas existentes & 90 dias \\
\hline Alaranjado & Médio & Melhorar as medidas existentes & 30 dias \\
\hline Vermeiho & Alto & Tomar medidas urgentes & 7 dias \\
\hline Preto & Critico & Adequar operação & Imediato \\
\hline
\end{tabular}

Fonte: Adaptada de Brown (1991), Guilherme (2005), Agência Europeia para a Segurança e a Saúde no Trabalho Avaliação de riscos : a chave para locais de trabalho seguros e saudáveis (2008); Freitas (2002). 
A etapa 4 é a de planejamento das ações, tendo por base a priorização obtida pela avaliação de riscos, assim definiram-se medidas a serem tomadas, a fim de eliminar e (ou) reduzir os riscos ou danos. Essas medidas podem ser feitas por meio de equipamentos de proteção coletivos, equipamentos de proteção individual, instrução e treinamentos ou até substituição do equipamento. Desta forma podem ser definidas uma ou mais medidas das apresentadas anteriormente dependendo da gravidade, do ambiente e da atividade realizada.

A etapa 5, de registro da avaliação, é onde são compilados todos os dados levantados e quais as medidas que devem ser tomadas para cada tipo de risco e atividade. Esta etapa deve ser feita de forma clara e acessível para qualquer pessoa. Deve estar disponível e ser de conhecimento de todos.

A etapa 6 é a de revisão da avaliação, recomenda-se fazer anualmente, quando houver mudanças de legislação, alterações de processo (novos materiais, tecnologias, instalações, substâncias etc.) em caso de acidentes ou incidentes e no caso de mudança de pessoal. Qualquer uma dessas situações pode criar ou alterar os riscos de segurança e saúde, portanto é essencial que as mudanças sejam gerenciadas.

\section{Resultado e discussão}

De acordo com os dados verificados na pesquisa os funcionários têm contato com materiais dos quatro grupos $\mathrm{A}, \mathrm{B}, \mathrm{C}$ e $\mathrm{D}$ classificados de acordo com o CONAMA 358/2005 e 257/1999;:

- Grupo A-Resíduos infectantes

- Grupo B - Resíduos Químicos

- Grupo C - Resíduos Radioativos

- Grupo D - Recicláveis e Não recicláveis

- Grupo E - Perfurocortantes.

Na tabela 1 pode ser verificado os tipos de resíduos encontrados nas áreas fabris:

Tabela 1. Tipos de resíduos gerados nas áreas fabris

\begin{tabular}{|l|l|}
\hline \multirow{2}{*}{ Áreas } & \multicolumn{1}{c|}{ Tipos de Resíduos/ Classificação } \\
\hline \multirow{4}{*}{ Refeitório } & Restos de alimentos - (D) \\
\cline { 2 - 3 } & Materiais Recicláveis (copos, plásticos, vidros, garrafas etc.) - (D) \\
\cline { 2 - 3 } & Materiais não recicláveis (guardanapos etc.) - (D) \\
\cline { 2 - 2 } & Produtos químicos para limpeza (detergente, sabão, álcool etc.) - (B) \\
\hline Ambulatório & Ferramentas de assistência à pessoas com contaminação biológica. - (A) \\
\hline
\end{tabular}




\begin{tabular}{|c|c|}
\hline & Remédios vencidos - (A) \\
\hline & Luvas de Procedimentos - (A) \\
\hline & Seringas, agulhas, lâminas etc - (E) \\
\hline \multirow{4}{*}{$\begin{array}{l}\text { Laboratório de } \\
\text { Microbiologia }\end{array}$} & Placas com Meio de Cultura - (A) \\
\hline & Luvas - (A) \\
\hline & Vidrarias Autoclaváveis - (E) \\
\hline & Vidrarias Diversas - $(\mathrm{E})$ \\
\hline \multirow{4}{*}{ Laboratório Físico Químico } & Reagentes - (B) \\
\hline & Vidrarias - (E) \\
\hline & Materiais Recicláveis (copos, plásticos, vidros, garrafas etc.) - (D) \\
\hline & Materiais não recicláveis (guardanapos etc.) - (D) \\
\hline \multirow{9}{*}{ Linhas de vidro } & Vidro $-(\mathrm{E})$ \\
\hline & Borra do rótulo (contaminado com soda) - (B) \\
\hline & Fita Plástica - (D) \\
\hline & Garrafeira Plástica - (D) \\
\hline & Madeira (pallets) - (D) \\
\hline & Lixo Comum - (D) \\
\hline & Tampa de metal - (D) \\
\hline & Radioativos $-(\mathrm{C})$ \\
\hline & Bombonas vazias de produtos químicos (limpeza, assepsia etc.) - (B) \\
\hline \multirow{6}{*}{ Linha de lata } & Latas de alumínio - (D) \\
\hline & Tampa de alumínio - (D) \\
\hline & Madeira (pallets) - (D) \\
\hline & Filme Plástico - (D) \\
\hline & Radioativos - $(\mathrm{C})$ \\
\hline & Bombonas vazias de produtos químicos (limpeza, assepsia etc.) - (B) \\
\hline \multirow{7}{*}{ Linhas de PET } & Garrafas PET - (D) \\
\hline & Tampa Plástica - (D) \\
\hline & Fita Plástica - (D) \\
\hline & Madeira (pallets) - (D) \\
\hline & Filme Plástico - (D) \\
\hline & Radioativos - (C) \\
\hline & Bombonas vazias de produtos químicos (limpeza, assepsia etc.) - (B) \\
\hline \multirow{6}{*}{ Oficina Mecânica/Elétrica } & óleo usado $-(\mathrm{B})$ \\
\hline & Materiais contaminados com óleo (estopa, pano etc.) - (B) \\
\hline & Metais - (D) \\
\hline & Componentes elétricos - (B) \\
\hline & Baterias e Pilhas - (B) \\
\hline & Fios elétricos $-(\mathrm{D})$ \\
\hline \multirow{6}{*}{ Utilidades } & Amônia - (B) \\
\hline & Etanol - (B) \\
\hline & Produtos químicos - (B) \\
\hline & Metais - (D) \\
\hline & óleo usado - (B) \\
\hline & Materiais contaminados com óleo (estopa, pano etc.) - (B) \\
\hline \multirow{2}{*}{ Processo de Produtivo } & Bombonas vazias de produtos químicos (limpeza, assepssia etc.) - (B) \\
\hline & Materiais Recicláveis (copos, plásticos, vidros, garrafas etc.) - (D) \\
\hline \multirow{6}{*}{ Logística } & Madeira (pallets) - (D) \\
\hline & Vidro (quebra) - (E) \\
\hline & Filmes plásticos - (D) \\
\hline & Fita Plástica - (D) \\
\hline & Latas de alumínio - (D) \\
\hline & Garrafas PET - (D) \\
\hline \multirow{3}{*}{ Almoxarifado } & Metais - (D) \\
\hline & Bombonas vazias de produtos químicos (limpeza, assepssia etc.) - (B) \\
\hline & Materiais Recicláveis (copos, plásticos, vidros, garrafas etc.) - (D) \\
\hline
\end{tabular}


Fonte: Os autores (2013).

A unidade fabril conta com um refeitório, um ambulatório médico, um laboratório de microbiologia, três laboratórios físico-químicos, uma oficina mecânica, uma oficina de empilhadeira, área de utilidades (frio, vapor, beneficiamento de $\mathrm{CO}_{2}$ ), uma estação de tratamento de água e uma estação de tratamento de efluente, reforma de pallets, área de carregamento (logística), almoxarifado de químicos, peças e insumos, processo produtivo, quatro linhas de garrafa de vidro, uma linha de lata, quatro linhas de PET e uma linha de barril de onde são coletados os resíduos que são destinados para a central de reciclagem.

Todo processo de destinação implantado na unidade fabril está de acordo com o exigido pelo CONAMA 358/2005 e 257/1999; porém, por muitas vezes, o processo de segregação não é bem feito pelos funcionários das áreas da fábrica, trazendo riscos para aqueles que trabalham na central de reciclagem durante a separação e coleta.

Outro procedimento padrão definido pela empresa é quanto à destinação de embalagens vazias que continham produtos químicos, que deve ser feito após a tríplice lavagem dessas embalagens, para evitar que fique qualquer resíduo do material químico. Porém, esse procedimento, da mesma forma que o outro, nem sempre é seguido pelos funcionários das áreas, tornando-se um risco grave para os operadores da central de reciclagem.

As áreas que apresentam maior risco durante a coleta são o ambulatório, onde os funcionários têm contato com resíduos microbiológicos e perfurocortantes; o laboratório, onde os funcionários têm contato com produtos químicos e resíduos microbiológicos; a linha de vidros e a logística, onde há grande quantidade de garrafas quebradas; e as áreas de estocagem de produtos químicos e materiais perigosos (óleos, tintas, amônia etc.). Durante a coleta nessas áreas os funcionários têm de utilizar todos os EPIs (Equipamentos de Proteção Individual) adequados.

Durante a avaliação da área e atividades realizadas pelos funcionários na central de reciclagem, identificaram-se nove situações consideradas de alto risco, 25 consideradas de médio risco e 19 de baixo risco. Após a definição e tomada das ações, registraram-se 15 riscos médios e 38 baixos.

De acordo com dados levantados pela pesquisa verificou-se que os funcionários não estavam capacitados para realização de suas atividades adequadamente do ponto de vista de segurança e meio ambiente, e foram tomadas medidas como treinamento e 
conscientização dos funcionários da fábrica sobre a importância de realizar a coleta seletiva adequadamente, como pode ser observado nas Figuras 4.

Figura 4. Funcionário participando de treinamento para conscientização de reciclagem.

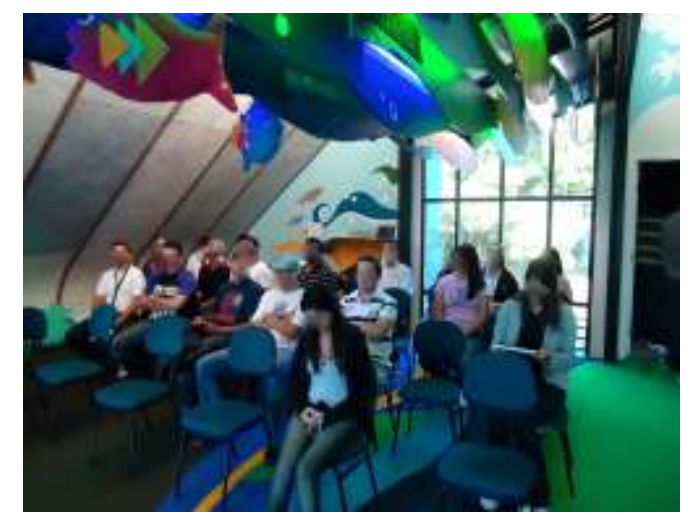

Como principais riscos tratados verificaram-se o contato com materiais perfurocortantes, pelos funcionários da área de central de reciclagem sem EPI adequando, sendo definido como EPI a luva de limalha de aço para uso durante a segregação de materiais que venham de áreas onde há materiais perfurocortantes. Vale lembrar que esta atividade causou um acidente com afastamento na área durante o ano 2012.

Observa-se, na Figura 5, que a segregação dos materiais não era realizada nas áreas da fábrica, e após treinamento na fabrica os materiais passaram a ser separados (figuras 6 e 7) uma vez que em um mesmo coletor se encontravam materiais de vários grupos e sem a correta segregação definida pelo CONAMA 358/2005 e 257/1999;:

Figura 5. Exemplo de material coletado e depositado no setor de envaze não separado adequadamente antes da realização de treinamento

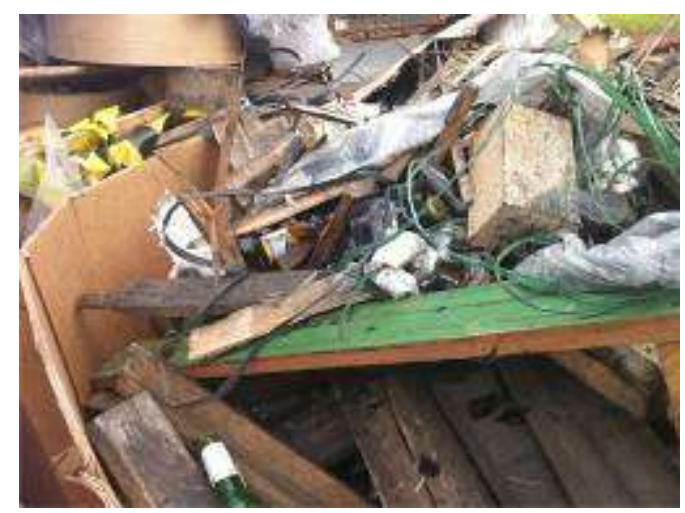


Figura 6. Exemplo de material plástico coletado e corretamente separado na linha de envaze após treinamento.

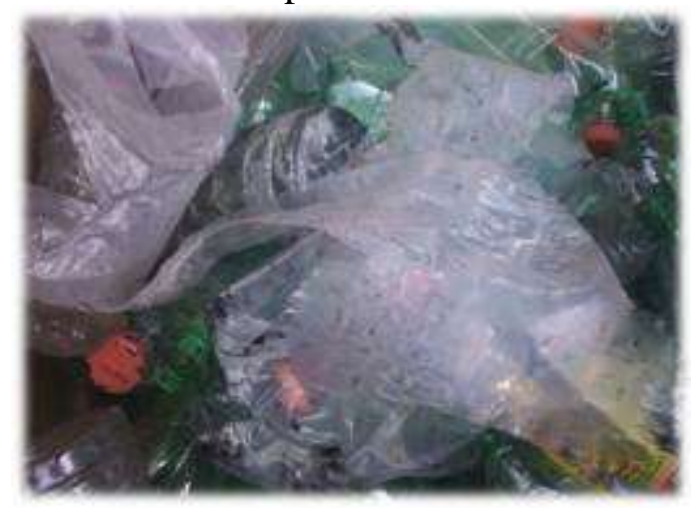

Figura 7. Exemplo de material de vidro coletado e corretamente separado na linha de envaze após treinamento.

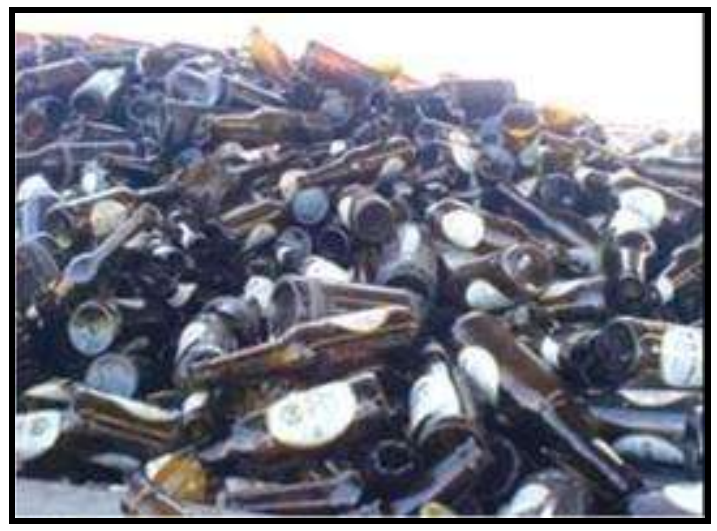

Para facilitar a realização da coleta seletiva nas áreas da fábrica, foram instalados também novos coletores (Figura 8), com melhor identificação de cores e com a descrição do material que pode ser jogado em cada lixeira.

Figura 8. Coletores identificados nas áreas da fábrica

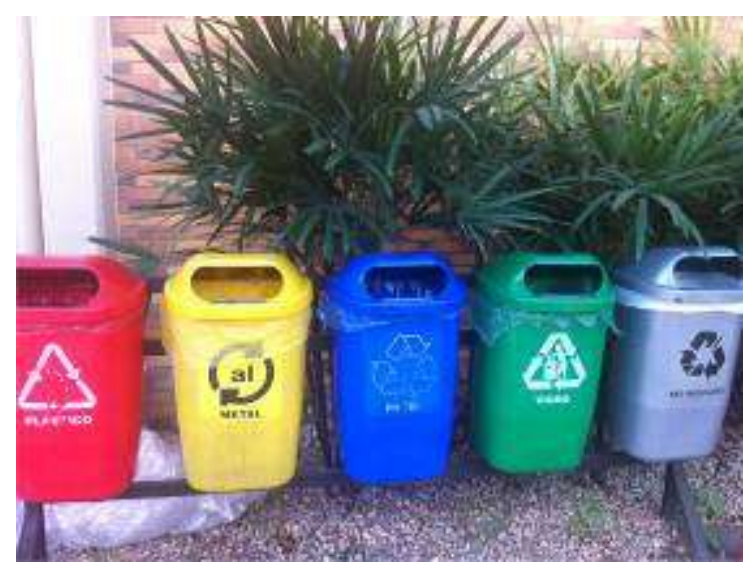


Identificou-se também o risco de atropelamento na área de central de reciclagem. Para minimizar esse risco, definiu-se o plano de tráfego da unidade, com a segregação de homem e máquina. Além da implantação da escola de empilhadeiras, pois todos os empilhadeiristas antes de iniciarem na função devem fazer o curso e o teste para desempenhar a atividade; e em caso de alguma atividade perigosa realizada, o funcionário também volta à escola para realizar uma reciclagem. Todos os motoristas devem ser habilitados e treinados, e no caso dos caminhoneiros, estes possuem carteira tipo C.

Outro risco identificado foi o de contato com produtos químicos, tanto nas áreas da fábrica onde os funcionários estão expostos a este tipo de resíduo (conforme descrito na tabela 1), quanto na área de central de reciclagem onde é feita a triagem de todos os materiais que vem da fábrica; risco este que durante o ano de avaliação chegou a causar um acidente com afastamento. Para evitar tal risco, foi realizado treinamento com todos os funcionários da fábrica para garantir que seja efetivada a tríplice lavagem das embalagens de químicos antes do envio para a central de reciclagem, além da definição dos EPIs adequados e instalação de chuveiro de emergência.

Outro risco relevante identificado foi contato com partes móveis de máquinas e equipamentos, e para este risco a medida tomada foi a instalação de sensores de segurança, chaves seccionadora para realizar o bloqueio do equipamento para realização de manutenção e limpeza e proteção de partes móveis. Todas as prensas e os moinhos foram adequados conforme as normas regulamentadoras NR10 e NR12. Corte durante a atividade de manutenção em moinho foi um dos acidentes causados, com afastamento no ano.

Outro risco identificado durante a análise foi a queda, tanto quedas do mesmo nível, relacionadas com a irregularidade dos pisos, falta de identificação de desníveis como degraus e piso molhado, quanto quedas de altura superior a 2 metros durante carregamento e enlonamento de caminhões..

\section{Considerações finais}

Com base na priorização obtida pela avaliação de risco, definiram-se regras e responsáveis para a operação segura em uma área de central de reciclagem, por meio do Por meio da avaliação realizada na área de central de reciclagem da empresa, com base nos métodos de análise preliminar de riscos (APR), análise de Métodos e Efeitos (AMFE) e 
análise de operabilidade de perigos (HAZOP), foram identificados 9 situações consideradas de alto risco, 25 consideradas de médio risco e 19 de baixo risco. Após a definição e tomada das ações, passou-se a 15 riscos médios e 38 baixos, o que garante a eficiência do processo de avaliação de risco pela metodologia proposta.

\section{Referências}

AGÊNCIA Europeia para a Segurança e a Saúde no Trabalho. Disponível em: <http://osha.europa.eu/topics/riskassessment>. Acesso em: 10 nov. 2012.

ANJOS, Luiz Antonio dos; FERREIRA, João Alberto. A avaliação da carga fisiológica de trabalho na legislação brasileira deve ser revista! O caso da coleta de lixo domiciliar. Cadernos de Saúde Pública, v.16, p.785-790, 2000.

ARAÚJO, Nelma Mirian Chagas de. Proposta de sistema de gestão da segurança e saúde no trabalho, baseado na OHSAS 18001 para empresas construtoras de edificações verticais. 2002. Tese (Doutorado) - Universidade Federal da Paraíba, João Pessoa, 2002.

BIRD, Frank E.; GERMAIN, George L. Practical loss control leadership. Loganville: Institute Publishing, 1987.

BRASIL. Decreto-Lei n. ${ }^{\circ} 5.452$, de $1 .^{\circ}$ de maio de 1943. Aprova a Consolidação das Leis do Trabalho. Disponível em: <http://www.planalto.gov.br/ccivil_03/decretolei/del5452.htm>. Acesso em: 15 dez. 2012.

. Ministério do Meio Ambiente. Resolução CONAMA. Disponível em: <http://www.mma.gov.br/port/conama>. Acesso em: 20 nov. 2012.

. Ministério do Trabalho e Emprego. Secretaria de Segurança e Saúde no Trabalho.

Portaria n. ${ }^{\circ}$ 25, de 29 de dezembro de 1994. Disponível em: <http://portal.mte.gov.br/data/files/FF8080812BE914E6012BEA44A24704C6/p_1994122 9_25.p f>. Acesso em: 20 nov. 2012.

BROWN, Anthony E. P. Curso de análise de risco. São Paulo, 1991.

CARDOZO, Mariana Caseño; LIEBER, Renato Rocha; DUTRA, Conceição Aparecida Matsumoto; BALESTIERI, José Antônio Perrella. Medidas de segurança em veículo para coleta de lixo urbano: condições para manobra em ré. Trabalho apresentado no XXV Encontro Nacional de Engenharia de Produção - Porto Alegre, RS, Brasil, 29 out. a 01 de nov. de 2005. Disponível em: <http://www.adepro.org.br/biblioteca/ ENEGEP2005 _Enegep0405_0756.pdf>. Acesso em: 13 jan. 2013. 
DE CICCO, Francesco. Manual sobre sistemas de gestão da segurança e saúde no trabalho: a nova norma BS 8800. São Paulo: Risk Tecnologia, 1996.

. Manual sobre sistemas de gestão da segurança e saúde no trabalho: OHSAS 18001. São Paulo: Risk Tecnologia, 1999.

DIAS, Luiz Alves; FONSECA, Manoel Santos. Plano de segurança e de saúde na construção. Lisboa: IDICT: IST, 1996.

ENGELS, Friedrich. A situação da classe trabalhadora na Inglaterra. São Paulo: Global, 1985. FREITAS, Carlos Machado de. Avaliação de riscos como ferramenta para a vigilância ambiental em saúde. Informe Epidemiológico do SUS, v.11, n.4, p.227-239, 2002.

GUILHERME, Luis Roberto Guimarães. Fundamentos da análise de risco. Biotecnologia Ciência e Desenvolvimento, n.34, p.44-55, jan./jun. 2005.

HINZE, Jimmie W. Construction safety. Englewood Cliffs: Prentice-Hall, 1997. INSTITUIÇÃO BRITANICA DE NORMAS - BSI. OHSAS 18001: Especificação para Sistemas de Gestão de Saúde Ocupacional e Segurança. Reino Unido, 1999. Disponível em: <http://pactoglobalcreapr.files.wordpress.com/2010/10/502_ohsas_ 180011.pdf>. Acesso em: 10 dez. 2012.

MTE. NR 10: Segurança em Instalações e Serviços em Eletricidade. Disponível em: < http://portal.mte.gov.br/data/files/8A7C812D308E216601310641F67629F4/nr_10.pdf >. Acesso em: 10 dez. 2012.

NR 12: Segurança no Trabalho em Máquinas e Equipamentos. Disponível em:

<http://portal.mte.gov.br/data/files/8A7C812D350AC6F801357BCD39D2456A/NR 12\%20(atualizada\%202011)\%20II.pdf >. Acesso em: 10 dez. 2012.

Política Nacional de Segurança e Saúde do Trabalhador. Brasília, 2004. Disponível em: <htpp://mte.gov.br>. Acesso em: 16 out. 2005.

OHSAS. OHSAS 18001:2007. OCCUPATIONAL HEALTH AND SAFETY MANAGEMENT SYSTEMS. REQUIREMENTS. OHSAS, 2007.

SANTOS, Zelãene dos. Segurança no trabalho e meio ambiente. Disponível em: <http://www.if.ufrgs.br/ mittmann/NR-9_BLOG.pdf em 22/02.2013>. Acesso em: 20 jan. 2013.

VELLOSO, Marta Pimenta; SANTOS, Elizabeth Moreira dos; ANJOS, Luiz Antonio dos. Processo de trabalho e acidentes de trabalho em coletores de lixo domiciliar na cidade do Rio de Janeiro, Brasil. Cadernos de Saúde Pública, v.13, n.4, p.693-700, 1997. 